\title{
Predictive Diagnostic Tools for the Development of New Onset Diabetes Mellitus after Transplantation: An Overview
}

\section{Phuong-Thu T Pham ${ }^{1 *}$ and Phuong-Chi T Pham ${ }^{2}$}

${ }^{1}$ Department of Medicine, Nephrology Division, Kidney Transplant Program, David Geffen School of Medicine at UCLA, Los Angels, CA 90095 ${ }^{2}$ Department of Medicine, Nephrology Division, UCLA-Olive View Medical Center, Sylmar, CA 91342

\begin{abstract}
New onset diabetes mellitus after transplantation (NODAT) is a serious and common complication following solid organ transplantation. NODAT has been reported to occur in $2 \%$ to $53 \%$ of all solid organ transplants. Kidney transplant recipients who develop NODAT have variably been reported to be at increased risk of fatal and nonfatal cardiovascular events and other adverse outcomes including infection, reduced patient survival, graft rejection, and accelerated graft loss compared with those who do not develop diabetes. Limited clinical studies in liver, heart, and lung transplants similarly suggested that NODAT has an adverse impact on patient and graft outcomes. Early detection and management of NODAT must, therefore, be integrated into the treatment of transplant recipients. Studies investigating the best predictive tool for identifying patients at risk for developing NODAT early after transplantation, however, are lacking. The clinical predictive values of fasting plasma glucose (FPG), oral glucose tolerance test (OGTT), and A1C in assessing the risk for the manifestation of NODAT are herein discussed.
\end{abstract}

Keywords: New onset diabetes after transplantation (NODAT); Fasting plasma glucose (FPG); Impaired fasting glucose (IFG); Impaired glucose tolerance (IGT); Oral glucose tolerance test (OGTT); Predictive diagnostic tools for NODAT; American Diabetes Association (ADA)

\section{Introduction}

The 2003 and updated 2005 International consensus guidelines recommended screening all transplant patients with fasting plasma glucose (FPG) as well as random plasma glucose at regular intervals (at least once a week for the first 4 weeks, then at 3,6, and 12 months then annually thereafter). In those with an intermediate FPG (defined as plasma glucose between 110-125 mg/dL; 6.1-6.9 mmol/L) and normal FPG (defined as FPG $<110 \mathrm{mg} / \mathrm{dL} ; 6.1 \mathrm{mmol} / \mathrm{L}$ ), a 2-hour oral glucose tolerance test (OGTT) should be considered [1,2]. However, the rationale for performing an OGTT in all patients with FPG $<110$ $\mathrm{mg} / \mathrm{dl}(6.1 \mathrm{mmol} / \mathrm{L})$ was not substantiated and such practice may entail testing a large number of patients which may be costly and impractical. It should also be noted that while the International consensus guidelines defined normal FPG as a plasma glucose of $<110 \mathrm{mg} / \mathrm{dL}(6.1 \mathrm{mmol} / \mathrm{L})$, the 2003 ADA expert committee had lowered the diagnostic threshold for impaired FPG to $\geq 100 \mathrm{mg} / \mathrm{dL}(5.6 \mathrm{mmol} / \mathrm{L})$.

The current article presents an overview of the literature on suggested screening strategies utilizing currently available glycemic tests including FPG, hemoglobin A1C (A1C) and OGTT to detect subclinical NODAT.

\section{The utility of FPG and OGTT in the screening and diagnosis of NODAT}

Armstrong et al. [3] were among the first to examine the predictive power of FPG with respect to 2 -hr blood glucose. A total of 200 previously nondiabetic renal transplant recipients who were at greater than 6 month post transplantation were included in the study. Patients with FPG $<126 \mathrm{mg} / \mathrm{dL}(7.0 \mathrm{mmol} / \mathrm{L} ; \mathrm{n}=188)$ underwent an OGTT. Receiver operating characteristics (ROC) analyses were used to evaluate the optimal level of FPG that was predictive of NODAT (2-hr blood glucose $\geq 200 \mathrm{mg} / \mathrm{dL} ; 11.0 \mathrm{mmol} / \mathrm{L}$ ) and impaired glucose tolerance (IGT) (2-hr blood glucose of $140-200 \mathrm{mg} / \mathrm{dL}$ or $7.8-11.0$ $\mathrm{mmol} / \mathrm{L}$ ). Forty two percent of study subjects were found to have an abnormal OGTT (NODAT in $11 \%$ and IGT in $29 \%$ ). The optimal FPG that was predictive of NODAT was $101 \mathrm{mg} / \mathrm{dL}$ ( $5.6 \mathrm{mmol} / \mathrm{L}$; area under the curve 0.70 ; sensitivity $64 \%$, specificity $67 \%$, positive predictive value $20 \%$, negative predictive value $93 \%$ ). The optimal FPG that was predictive of IGT was less well defined (area under the curve 0.54). The prevalence of NODAT was higher by OGTT than by FPG alone $(17 \%$ vs $6 \% ; \mathrm{P}<0.0001)$. However, it is noteworthy that more than $90 \%$ of the study population was white. Inclusion of more patients with diverse ethnic background might have altered the reported prevalence of NODAT and IGT by oral glucose tolerance testing. Nonetheless, the results of the study suggested that FPG may not be the optimal screening or diagnostic tool for NODAT or IGT due to its lack of sensitivity and specificity. Hence, the authors proposed that OGTT should be considered as a routine screening test in all renal transplant recipients.

In a prospective study that was designed to evaluate the use of OGTT for risk-stratifying patients for NODAT, Sharif et al. [4] demonstrated that among 122 renal transplant recipients without diabetes who had two FPG level measurements within the range 100-125 mg/dl (5.6-6.9 $\mathrm{mmol} / \mathrm{L}$ ) more than 6 months after transplantation, OGTT revealed that $10 \%$ had overt DM, $9 \%$ had IGT alone, $18 \%$ had impaired fasting glucose (IFG) alone (all defined by World Health Organization criteria), and $14 \%$ had combined IFG and IGT. In agreement with most studies, the results of this study demonstrated that FPG underestimates the prevalence of NODAT and IGT. Hence, it was suggested that the routine use of OGTT in renal transplant recipients is a valuable clinical tool in risk stratifying patients for the development of NODAT.

Kuypers et al. [5] evaluated the utility of determining FPG levels and performing an oral glucose tolerance test (OGTT) in the early post transplantation period for the prediction of NODAT development.

*Corresponding author: Phuong-Thu T Pham, Clinical Associate Professor of Medicine, Director of Outpatient Services, Department of Medicine, Nephrology Division, Kidney Transplant Program, David Geffen School of Medicine at UCLA, Los Angeles, CA 90095, E-mail: PPham@mednet.ucla.edu

Received July 25, 2011; Accepted August 02, 2011; Published September 26 2011

Citation: Pham PT, Pham PC (2011) Predictive Diagnostic Tools for the Development of New Onset Diabetes Mellitus after Transplantation: An Overview. J Transplant Technol Res 1:103e. doi:10.4172/2161-0991.1000103e

Copyright: ( 2011 Pham PT, et al. This is an open-access article distributed under the terms of the Creative Commons Attribution License, which permits unrestricted use, distribution, and reproduction in any medium, provided the original author and source are credited. 
Citation: Pham PT, Pham PC (2011) Predictive Diagnostic Tools for the Development of New Onset Diabetes Mellitus after Transplantation: An Overview. J Transplant Technol Res 1:103e. doi:10.4172/2161-0991.1000103e

Page 2 of 4

The 2003 American Diabetes Association (ADA) criteria were used to define IGT, IFG, and diabetes mellitus (DM). NODAT was defined as the uninterrupted need for glucose-lowering therapy for at least 3 months following transplantation. Renal allograft recipients with preexisting DM were excluded from the study. All patients in the study completed an OGTT 5 days after transplantation, as stipulated by the World Health Organization (WHO). In total, 359 eligible de novo renal transplant recipients were enrolled in the study. At a mean follow-up of $42.8 \pm 16.9$ months, 64 patients $(17.8 \%)$ had developed NODAT.
A normal (vs diabetic) OGTT at 5 days after transplantation was associated with a reduced risk of NODAT (odds ratio 0.03; $\mathrm{P}=0.0002$ ). A similar risk reduction was conferred by a normal (vs diabetic) FPG level on day 5 (odds ratio $0.06 ; \mathrm{P}=<0.0001$ ). The OGTT on day 5 had better sensitivity $(93.4 \%$ vs. $21.6 \%)$ and a higher negative predictive value $(97.6 \%$ vs. $89.1 \%)$ than FPG test on day 5 , but poorer specificity (71.9\% vs. $97.6 \%)$ and a lower positive predictive value $(47.2 \%$ vs. $61.5 \%)$. For transplant recipients who developed NODAT very early following transplantation, the concern arose that the OGTT on day 5

\begin{tabular}{|c|c|c|c|c|}
\hline Study protocols & $\begin{array}{l}\text { Demographic } \\
\text { characteristics }\end{array}$ & Study results & Conclusions & References \\
\hline $\begin{array}{l}\text { FPG and OGTT } \\
\mathrm{N}=200>6 \text { mo. postTx, } \\
\text { OGTT performed in } \\
\text { patients with FPG }<7.0 \\
\mathrm{mmol} / \mathrm{L}(\mathrm{n}=188)\end{array}$ & White $>90 \%$ & $\begin{array}{l}\text { ROC analyses } \\
\text { Optimal FPG predictive of NODAT: } 101 \mathrm{mg} / \mathrm{dL} ; 5.6 \\
\text { mmol/L (AUC= } 0.70 \text {; sensitivity } 64 \% \text {; specificity } \\
67 \% \text {, positive predictive } 20 \% \text {; negative predictive } \\
93 \% \\
\text { Optimal FPG predictive of IGT less well-defined } \\
\text { (AUC=0.54) } \\
\text { Prevalence of NODAT (OGTT vs. FPG alone } 17 \% \\
\text { vs. } 6 \% \text {, respectively; P<0.0001) }\end{array}$ & $\begin{array}{l}\text { FPG may not be the optimal screening or } \\
\text { diagnostic tool due to lack of sensitivity \& } \\
\text { specificity } \\
\text { OGTT should be considered as a routine } \\
\text { screening test in all renal transplant recipients }\end{array}$ & Armstrong et al. \\
\hline $\begin{array}{l}\text { FPG and OGTT } \\
\text { N=122 > } 6 \text { months } \\
\text { postTx } \\
\text { OGTT performed in } \\
\text { patients with } 2 \text { FPG } \\
\text { values between } 5.6-6.9 \\
\text { mmol/L }\end{array}$ & $\begin{array}{l}\text { White } 96 \% \\
\text { Asian } 3 \% \\
\text { Afro-Caribbean } 1 \%\end{array}$ & $\begin{array}{l}\text { OGTT revealed } 10 \% \text { had overt DM, } 9 \% \text { IGT alone, } \\
18 \% \text { IFG alone, } 14 \% \text { combined IFG and IGT }\end{array}$ & $\begin{array}{l}\text { FPG underestimates IGT and NODAT } \\
\text { prevalence } \\
\text { Routine use of OGTT is a valuable clinical } \\
\text { tool to risk stratify patient for NODAT }\end{array}$ & Sharif et al. \\
\hline $\begin{array}{l}\text { FPG and OGTT } \\
\mathrm{N}=359 \\
\text { All pts completed OGTT } \\
5 \text { days potTx } \\
\text { Mean f/u: } 42.8 \pm 16.9 \\
\text { months }\end{array}$ & $\begin{array}{l}\text { White } 91.4 \% \\
\text { Blacks } 1.4 \% \\
\text { Arabic } 7.2 \% \\
\text { Hispanics } 0 \%\end{array}$ & $\begin{array}{l}\text { - } 17.8 \% \text { developed NODAT } \\
\text { A normal (vs. diabetic) OGTT at day } 5 \text { postTx } \\
\text { associated with } \downarrow \text { NODAT risk (OR= } 0.03 \text {; } \\
P=0.0002 \text { ) } \\
\text { Sensitivity } 93.4 \% \text {; Specificity } 71.9 \% \\
\text { A normal (vs diabetic) FPG on day } 5 \text { associated } \\
\text { with } \downarrow \text { NODAT risk (OR= } 0.06 \text {; } P<0.0001 \text { ) } \\
\text { Sensitivity } 21.6 \% \text { Specificity } 97.6 \%\end{array}$ & $\begin{array}{l}\text { A normal FPG (vs. diabetic) and a normal } \\
\text { OGTT (vs diabetic) at } 5 \text { days postTx seems } \\
\text { to identify patients at } \downarrow \text { NODAT risk }\end{array}$ & Kuypers et al. \\
\hline $\begin{array}{l}\text { FPG and A1C } \\
\begin{array}{l}\mathrm{N}=199 \geq 3 \text { months } \\
\text { postTx }\end{array} \\
\begin{array}{l}\text { All patients had a history } \\
\text { of normal FPG prior to } \\
\text { study }\end{array} \\
\begin{array}{l}\text { Normal A1C defined as } \\
<6.1 \%\end{array}\end{array}$ & $\begin{array}{l}\text { African Americans } \\
81.9 \%\end{array}$ & 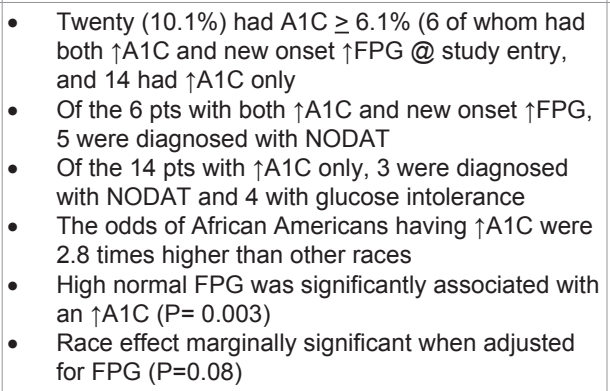 & $\begin{array}{l}\text { A1C level was a more sensitive test than } \\
\text { FPG in detecting NODAT } \\
\text { A1C testing should be considered as a } \\
\text { screening test for NODAT, especially in } \\
\text { African Americans }\end{array}$ & Hoban et al. \\
\hline $\begin{array}{l}\text { FPG, A1C, and OGTT } \\
\text { N=929 @ 10-week } \\
\text { postTx } \\
\text { Patients who had } \\
\text { both FPG }<7.0 \mathrm{mmol} / \mathrm{L} \\
\text { and A1C levels available } \\
\text { were evaluated }\end{array}$ & White $95 \%$ & $\begin{array}{l}\text { ROC analysis: } \\
\text { FPG: AUC } 0.761(95 \% \mathrm{Cl} 0.714-0.809) \\
\text { A1C: AUC } 0.817(95 \% \mathrm{Cl} 0.758-0.876) \\
\text { Performing OGTT on patients with FPG } \geq 5.3 \mathrm{mmol} / \mathrm{L} \\
\text { or A1C } \geq 5.8 \% \text { predicted NODAT with } 81 \% \text { and } 83 \% \\
\text { sensitivity, requiring } 49 \% \text { and } 41 \% \text { of the patients to be } \\
\text { tested, respectively } \\
\text { Combined criterion of FPG } \geq 5.0 \mathrm{mmol} / \mathrm{L} \text { and } \mathrm{A} 1 \mathrm{C} \geq \\
5.7 \% \text { provided a sensitivity of } 79 \% \text { from testing } 29 \% \text { of } \\
\text { the population }\end{array}$ & $\begin{array}{l}\text { OGTT should be considered in patients with } \\
\text { FPG between } 5.3-6.9 \mathrm{mmol} / \mathrm{L} \text { or } \mathrm{A} 1 \mathrm{C} \geq 5.8 \% \\
\text { or } \\
\text { In those with combined } \mathrm{FPG} \geq 5 \mathrm{mmol} / \mathrm{L} \text { and } \\
\mathrm{A} 1 \mathrm{C} \geq 5.7 \%\end{array}$ & $\begin{array}{l}\text { Valderhaugh } \\
\text { et al. }\end{array}$ \\
\hline
\end{tabular}

Abbreviations: PostTx: post transplant; ROC: receiver operating characteristics; AUC: area under the curve

Table 1: Clinical studies evaluating the predictive diagnostic tools for the development of NODAT. 
served merely as a diagnostic rather than a predictive tool. However, a multivariate analysis involving only those who developed NODAT two or more weeks after the OGTT revealed a similar significant association between a normal OGTT and a reduced risk for "delayed" NODAT. The results of the study suggested that a normal FPG (vs. diabetic) and a normal OGTT (vs. diabetic) at 5 days after transplantation seems to identify recipients at reduced risk for NODAT at least among white subjects $(91.4 \%$ of the study population were white, $1.4 \%$ were blacks and Hispanics were absent). These findings have yet to be validated in blacks and Hispanics.

\section{The utility of FPG and A1C in the screening and diagnosis of NODAT}

The 2010 American Diabetes Association (ADA) Expert Committee has adopted an A1C level of $\geq 6.5 \%$ as an alternative diagnostic criterion for diabetes mellitus (DM) in the general population based on the observed association between $\mathrm{A} 1 \mathrm{C}$ level and the risk for future development of retinopathy. A1C levels between $5.7 \%$ and $6.4 \%$ are considered high risk for DM. The use of $\mathrm{A} 1 \mathrm{C}$ as a screening or diagnostic tool in the setting of organ transplantation has yet to be validated.

Hoban et al. [6] first described the utility of A1C in the detection of subclinical NODAT in recipients of kidney transplant recipients. The study consisted of 199 previously non diabetic adult kidney transplant recipients who were $\geq 3$ months post transplant (one subject was enrolled at 73 days post transplant). All study subjects were required to have a history of normal FPG (not defined) prior to study entry. Patients with recent blood transfusion or blood loss that might affect A1C measurements were excluded. A normal A1C was defined as an A1C of $<6.1 \%$. Of 199 patients studied, 20 (10.1\%) were found to have an $\mathrm{A} 1 \mathrm{C} \geq 6.1 \%$, six of whom had both elevated $\mathrm{A} 1 \mathrm{C}$ and new onset elevated FPG at study entry despite a history of normoglycemia. In clinical follow-up (6.9 years post transplant), 13 of the 20 (all 6 patients with both elevated FPG and A1C) and 7 of the 14 patients with only elevated $\mathrm{A} 1 \mathrm{C}$ had medical intervention for diabetes or glucose intolerance. Of the six patients with elevated A1C and FPG, five were eventually diagnosed with $\mathrm{DM}$ at long-term follow-up. Of the 14 patients with elevated $\mathrm{A} 1 \mathrm{C}$ and normal screening FPG, 3 were diagnosed with DM and 4 with glucose intolerance. Notably, the odds of African Americans having an elevated A1C were 2.8 times higher than those of other races, with $19.4 \%$ of African Americans having elevated A1C compared with $8 \%$ of their non-African American counterpart. However, multivariate logistic regression analysis demonstrated that high normal FPG was significantly associated with an elevated A1C $(\mathrm{P}=0.003)$, whereas race effect was only marginally significant when adjusted for FPG $(\mathrm{P}=0.08)$. The investigators concluded that $\mathrm{A} 1 \mathrm{C}$ level was a more sensitive test than FPG in detecting NODAT and further validated this recommendation in African Americans. Of note, African Americans predominated the study population (81.9\%).

\section{The utility of FPG, A1C and OGTT in the screening and diagnosis of NODAT}

In a single center study consisting of 1637 previously non diabetic renal transplant recipients who were prospectively examined 10 -week after transplantation, 66 patients were found to have manifest NODAT and OGTT was not performed in these patients. The remaining 1571 patients with previously normal FPG underwent an OGTT. Of these, $213(14 \%)$ were diagnosed with NODAT, $51 \%$ of whom $(n=109)$ were identified by 2 -hr PG $\geq 11.1 \mathrm{mmol} / \mathrm{L}$ alone, and $17 \%(\mathrm{n}=35)$ by FPG alone (FPG $\geq 7.0 \mathrm{mmol} / \mathrm{L})$. Sixty nine patients $(32 \%)$ fulfilled both criteria for NODAT. To assess the diagnostic accuracy of FPG and A1C to predict a 2-hr PG $>11.1 \mathrm{mmol} / \mathrm{L}$, Valderhaugh et al. [7] analyzed a subgroup of patients with a FPG of $<7 \mathrm{mmol} / \mathrm{L}$ and in whom A1C levels were available $(\mathrm{n}=929)$. Receiver operating characteristic analysis revealed an area under the curve of 0.761 (95\% CI 0.714-0.809) for FPG and 0.817 (95\% CI 0.758-0.876) for A1C. Performing an OGTT on patients with a FPG $\geq 5.3 \mathrm{mmol} / \mathrm{L}$ or $\mathrm{AlC} \geq 5.8 \%$ predicted diabetes with $81 \%$ and $83 \%$ sensitivity, requiring $49 \%$ and $41 \%$ of the patients to be tested, respectively. The combined criteria of FPG $\geq 5.0 \mathrm{mmol} / \mathrm{L}$ and $\mathrm{A} 1 \mathrm{C} \geq 5.7 \%$ provided similar sensitivity (79\%) from testing only $29 \%$ of the population. The authors concluded that OGTT should be considered in patients with a FPG between 5.3-6.9 mmol/L or HbAlc $\geq 5.8 \%$ or in those with combined FPG $\geq 5.0 \mathrm{mmol} / \mathrm{L}$ and $\mathrm{A} 1 \mathrm{C} \geq 5.7 \%$. However, the authors acknowledged that $95 \%$ of the study populations were white and the study results might not be valid for patients of other ethnicities.

Clinical studies evaluating the predictive diagnostic tools for the development of NODAT is summarized in Table 1.

\section{The utility of FPG, A1C, and OGTT in the screening and diagnosis of NODAT: The authors' perspectives}

Literature review suggests that similar to the general population, the 2-hr OGTT diagnostic criteria may be more sensitive in identifying patients with IGT or NODAT than those set for FPG. However, screening all renal transplant patients with OGTT may be costly and difficult to realize in clinical practice. The introduction of $\mathrm{A} 1 \mathrm{C}$ as an additional optional diagnostic criterion for diabetes mellitus in the general population has also sparked interest in its use as a screening and diagnostic tool in renal transplant recipients. One single-center study suggested that A1C level was a more sensitive test than FPG in detecting NODAT, particularly in African Americans (discussed in previous section). However, the majority of patients in the study were African Americans. The utility of A1C as the routine screening or diagnostic tool in identifying patients with NODAT requires further studies.

In the authors' opinion, OGTT should be considered in patients with multiple risk factors for NODAT, whereas FPG or A1C or both can be used to screen or risk stratify patients and should be monitored in all renal transplant recipients at regular intervals [8,9]. However, standardized, validated assays for A1C testing should be used. It should be noted that $\mathrm{A} 1 \mathrm{C}$ cannot be accurately interpreted within the first 3 months post-transplantation due to various factors including possible blood transfusions in the early post-transplant period and the presence of anemia or impaired graft function. Blood transfusions may render the test invalid while anemia and kidney impairment can directly interfere with the $\mathrm{A} 1 \mathrm{C}$ assay. In islet cell transplant recipients, an artifactual reduction in $\mathrm{A} 1 \mathrm{C}$ level has been reported in recipients receiving dapsone for Pneumocystis carinii (P. jiroveci) prophylaxis. The cause is unknown but a reduction in red cell life span or hemolysis or both has been implicated.

Available literature suggests that similar to the nontransplant settings, the risk for developing NODAT appears to follow a continuum across the entire spectrum of subdiabetic glycemic values. Renal transplant recipients with higher FPG values or higher A1C levels may convey higher NODAT risk compared with those with lower values. Hence, OGTT should also be considered in the former groups at the discretion of the clinicians. Suggested guidelines for NODAT screening are summarized in Figure 1.

More recently, new onset hyperglycemia in the immediate postoperative period (inpatient hyperglycemia) defined as bedside capillary glucose of $\geq 200 \mathrm{mg} / \mathrm{dL}$ on at least 1 measurement, or the 
Citation: Pham PT, Pham PC (2011) Predictive Diagnostic Tools for the Development of New Onset Diabetes Mellitus after Transplantation: An Overview. J Transplant Technol Res 1:103e. doi:10.4172/2161-0991.1000103e

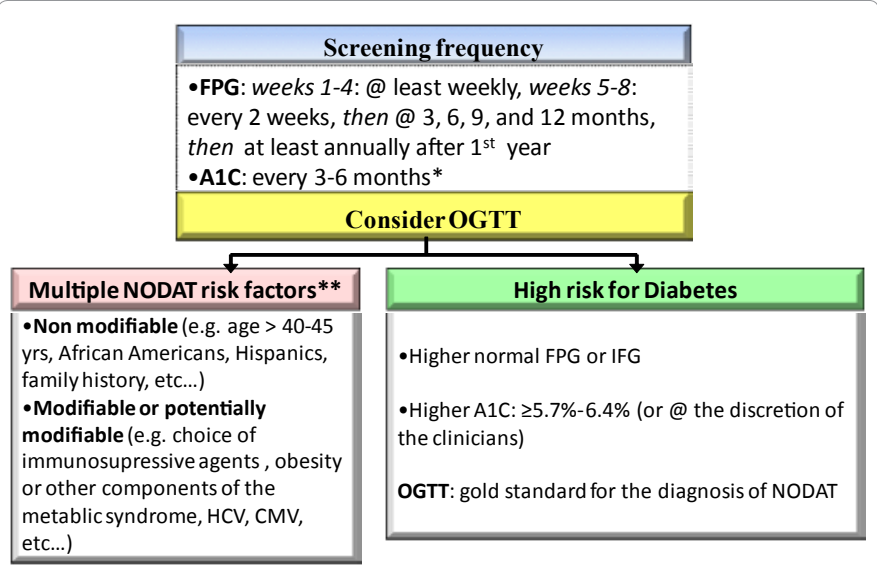

Abbreviations: HCV: hepatitis C; CMV: cytomegalovirus

*See text for factors that may affect A1C measurements **NODAT risk factors reviewed in reference 9

Figure 1: Suggested guidelines for NODAT screening

administration of insulin therapy at any time during the hospital stay has also been suggested to be predictive of future NODAT risk [10]. Among 377 primary kidney transplant recipients with at least 1-year follow-up, NODAT developed in $4 \%$ of patients without inpatient hyperglycemia, $18 \%$ of patients with inpatient hyperglycemia but not treated with insulin, and in $30 \%$ of patients who were diagnosed with inpatient hyperglycemia and treated with insulin. Whether all patients with new onset hyperglycemia in the immediate post-operative period should undergo OGTT at long-term follow-up remains to be studied.

Lastly, while the preferred glycemic tests (FPG vs. A1C vs. OGTT) used for screening or diagnosing NODAT or both may differ among centers, it should be noted that currently, OGTT has been advocated as the gold standard test for the diagnosis of NODAT.

\section{References}

1. Davidson J, Wilkinson A, Dantal J, Dotta F, Haller H, et al. (2003) New-onset diabetes after transplantation: 2003 International Consensus guidelines 1 Transplantation 75: SS3-SS24.

2. Wilkinson AH, Davidson J, Dotta F, Home PD, Keown P, et al. (2005) Guidelines for the treatment and management of new-onset diabetes after transplantation. Clin Transplant 19: 291-298.

3. Armstrong KA, Prins JB, Beller EM, Campbell SB, Hawley CM, et al. (2006) Should an oral glucose tolerance test be performed routinely in all renal transplant recipients? Clin J Am SocNephrol 1: 100-108.

4. Sharif A, Moore RH, Baboolal K (2006) The use of oral glucose tolerance tests to risk stratify for new-onset diabetes after transplantation: An under diagnosed phenomenon. Transplantation 82: 1667-1672

5. Kuypers DR, Claes Kathleen, Bammens B, Evenepoel P, Vanrenterghem Y (2008) Early clinical assessment of glucose metabolism in renal allograft recipients: diagnosis and prediction of post-transplant diabtes mellitus (PTDM) Nephrol Dial Transplant 23: 2033-2042.

6. Hoban R, Gielda B, Temkit M, Saha C, Book B, et al. (2006) Utility of HbA1c in the detection of subclinical post renal transplant diabetes. Transplantation 81: 379-383.

7. Valderhaug TG, Jensen T, Hartmann A, Midtvedt K, Holdaas H, et al. (2009) Fasting plasma glucose and glycosylated hemoglobin in the screening for diabetes mellitus after renal transplantation. Transpantation 88: 429-434.

8. Pham PT and Pham PC (2008) Assessing the risk of post-transplantation diabetes mellitus with an oral glucose tolerance test. Nature Clin Practice 4 $600-601$.

9. Pham PT, Pham PM, Pham SV, Pham PA, Pham PC (2011) New Onse Diabetes after Transplantation (NODAT): An Overview. Diabetes Metab Syndr Obes 4: 175-186.

10. Chakkera HA, Knowler WC, Devarapalli Y, Weil EJ, Heilman RL, et al. (2010) Relationship between inpatient hyperglycemia and insulin treatment after kidney transplantation and future new onset diabetes mellitus. Clin J Am Soc Nephrol 5: 1669-1675 